\title{
Review
}

\section{Ethical considerations in elderly patients with acute coronary syndrome}

\author{
Ana Ayesta ${ }^{1}$, Clara Bonanad $^{2}$, Pablo Díez-Villanueva ${ }^{3}$, Sergio García-Blas $^{2}$, \\ Albert Ariza-Solée, Manuel Martínez-Sellés ${ }^{5,6,7, *}$ \\ ${ }^{1}$ Heart Area, Hospital Universitario Central de Asturias, 33011 Oviedo, Asturias, Spain \\ ${ }^{2}$ Cardiology Department, Hospital Clínico Universitario de Valencia, INCLIVA Biomedical Research Institute, 46010 Valencia, Spain \\ ${ }^{3}$ Cardiology Department, Hospital Universitario La Princesa, 28006 Madrid, Spain \\ ${ }^{4}$ Cardiology Department, Hospital Universitari de Bellvitge, L'Hospitalet de Llobregat, 08907 Barcelona, Spain \\ ${ }^{5}$ Cardiology Department, Hospital General Universitario Gregorio Marañón, Centro de Investigación Biomédica en Red Cardiovascular (CIBERCV), \\ 28007 Madrid, Spain \\ ${ }^{6}$ School of Medicine, Universidad Complutense de Madrid, 28040 Madrid, Spain \\ ${ }^{7}$ School of Biomedical Sciences, Universidad Europea de Madrid, 28670 Madrid, Spain \\ *Correspondence: mmselles@secardiologia.es (Manuel Martínez-Sellés) \\ Academic Editor: Peter A. McCullough \\ Submitted: 1 November 2021 Revised: 10 December 2021 Accepted: 17 December 2021 Published: 11 February 2022
}

\begin{abstract}
Acute coronary syndrome (ACS) is one of the main causes of mortality and morbidity in the elderly. The prevalence of ACS increases with age and patients with advanced age have some co-morbidities that require an individualized approach, which includes a comprehensive geriatric assessment. Ageism is a matter of great concern. In this scenario, some ethical conflicts may arise which should be anticipated, considered, and solved. Clinicians will need to prioritize and allocate resources, to avoid futility/proportionality, which is not always easy to assess in these patients. This review aims to summarize the evidence regarding ethical conflicts that may arise in the management of patients with ACS and advanced age. We will discuss how to choose the best option (which frequently is not the only one) with the lowest risk for harm, considering and respecting the patients' decision. The four basic principles of bioethics (beneficence, non-maleficence, autonomy, and justice) are thoroughly reviewed, and discussed, regarding their role in the decision making process.
\end{abstract}

Keywords: Ethics; Acute coronary syndrome; Ageism; Prioritization; Futility

\section{Introduction}

Acute coronary syndrome (ACS) is one of the main causes of mortality and morbidity in the elderly. The prevalence of ACS increases with age and is associated with a poor prognosis $[1,2]$. The lengthening of life expectancy, and the appearance of new treatments that improve the survival of patients with ischemic heart disease have increased the number of elderly patients with ACS. Patients with advanced age have co-morbidities $[3,4]$ that make individualized management essential. In this complex scenario, some ethical conflicts may arise which should be anticipated, considered, and solved.

This review aims to summarize the published evidence regarding ethical conflicts that may arise in the management of elderly patients with ACS and how they can be managed according to different bioethical principles [5-7]. Decisions in elderly patients with ACS, as in their younger counterparts, should be based on the basic principles of bioethics (beneficence, non-maleficence, autonomy, and justice) [5]. This implies that clinicians should choose the best option for each patient to avoid harm, and to consider and respect his/her decision using the proper allocation of resources. Topics such as ageism, prioritization, and futility will also be reviewed.

\section{Ageism, professionalism, and the principles of beneficence and autonomy}

\subsection{Ageism and its influence on health}

Ageism is the practice of stereotyping, prejudice, and/or discrimination against individuals or groups based on their age. It includes any attitude, action, or institutional structure that discriminates against a person or group of people exclusively because of their age [8]. Given that age is only a weak predictor of outcomes in critically ill patients, the decision to treat based only on the patient's age is unacceptable [5]. Ageism is a widely spread attitude that has a detrimental effect on health [9-11]. There are three of components of ageism that can affect health: (1) discrimination when receiving certain treatments (unjustified donot-resuscitate-orders [12], administration of cheaper treatments [13], lower quality treatments [14] ...); (2) negative stereotyping; and (3) negative self-perception of aging itself. These components influence psychological and behavioral mechanisms. Ageism might be structural (promoted by institutions), and individual (due to assimilated negative beliefs about age) [9]. In a recent meta-analysis [9] both structural and individual ageism influenced health through different domains, with a worse health outcome involving ageism in $96 \%$ of the analyzed studies. Structural attitudes include exclusion from clinical trials and research studies, 


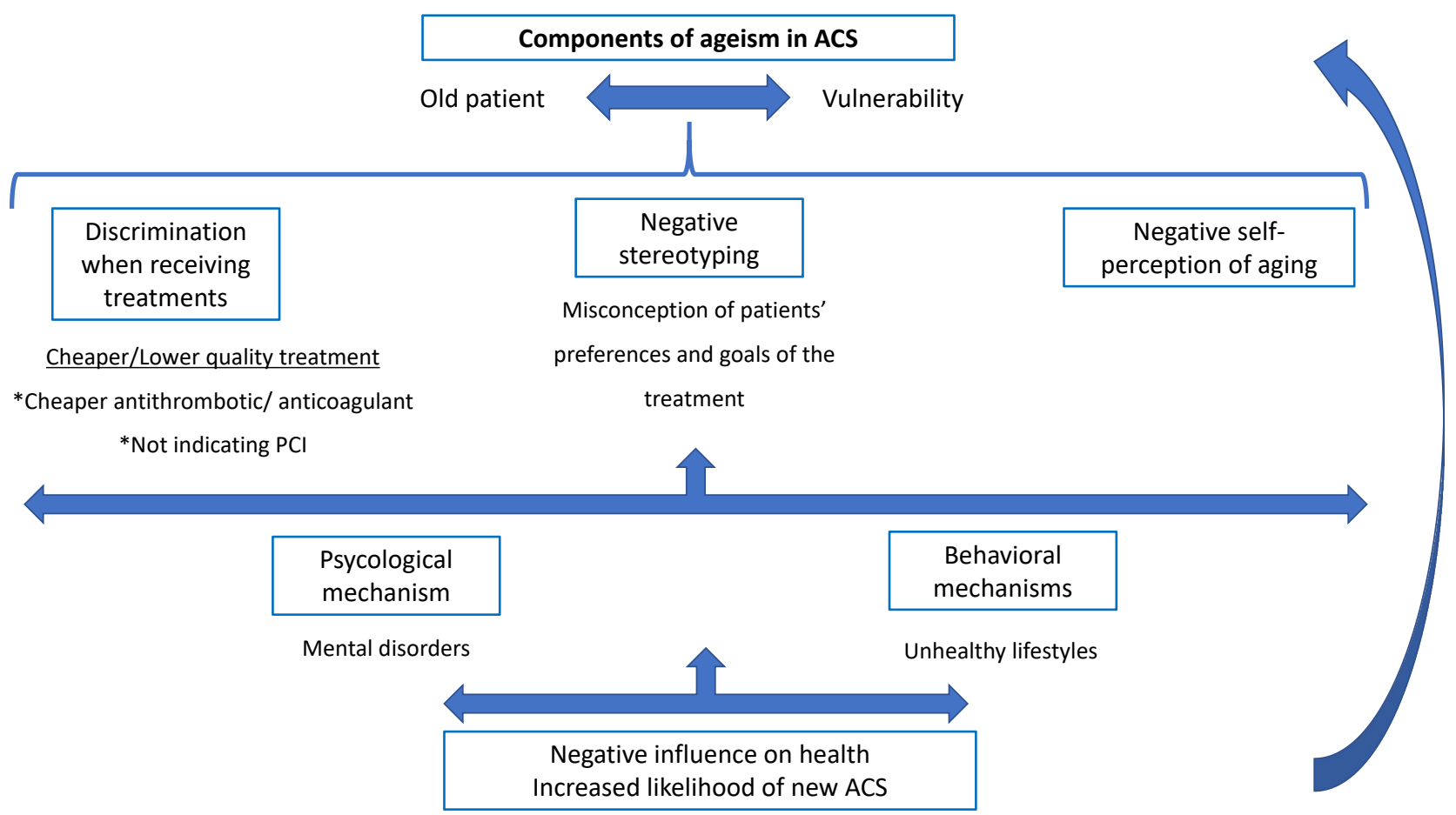

Fig. 1. Components of ageism and its influence on outcomes in acute coronary syndrome. Ageism is well related to the concept of vulnerability, and it has three components that can be noted in the management of acute coronary syndrome. The elderly may receive lower quality treatment due to its price; the preferences and goals of the patient may not be considered, and a negative self-perception of aging may appear. These may lead to mental disorders and unhealthy lifestyles with an increased likelihood of a new acute coronary syndrome.

denial of medical assistance or treatment, and non-medical attitudes such as devaluation of life and lack of employment opportunities. Surprisingly, the detrimental effect of ageism on health is even stronger than the well-known negative effect of racism [15].

Ageist attitudes, especially in medicine, might be related to the misconception of elderly people as vulnerable individuals. This misconception is derived from negative stereotypes of advanced age in terms of helplessness and dependence. Vulnerability [16] is defined as increased susceptibility to damage. Advanced age is not a synonym of vulnerability. Most elderly persons have reached sufficient maturity and passed certain stages of life that would allow them to increase their economic relevance, cultural influence, and political representation. However, aging increases the probability of suffering injury due to low reserve and frailty. Nevertheless, the elderly maintain development potential and can acquire capacities to fight against certain aggressions, so chronological age should not be considered the only vulnerability criterion.

The different components of ageism found in the ACS healthcare process and their influence on major outcomes are shown in Fig. 1.

\subsection{Ageism and management of ACS}

The incidence of ACS will progressively increase with aging of the population, and will produce an increase in the number of elderly patients admitted with ACS. Thus, it is very important to consider the correct decision-making processes to follow for this specific population [17]. Ageist attitudes may arise at different points in the diagnosis and treatment of ACS, either when deciding on antithrombotic medical treatment, the indication for percutaneous revascularization, or the site of admission (cardiology ward versus acute care units). Table 1 details ageist attitudes in the healthcare process involving patients with ACS.

Current guidelines recommend coronary angiography and, if indicated, percutaneous coronary intervention (PCI) $[18,19]$ in patients with ST-segment-elevation myocardial infarction (STEMI) and non-ST-segment elevation of myocardial infarction (NSTEMI) irrespective of age. However, in the case of NSTEMI, the elderly population is underrepresented in clinical trials [20], even more so in patients with advanced age and geriatric syndromes [21] and comorbidities. Thus, PCI in this population could be controversial and requires careful individual assessment. The lack of evidence and some ageist attitudes may explain why the elderly are less likely to be treated with PCI than younger patients, even when confounding factors are con- 
Table 1. Ageist attitudes in the health care process of acute coronary syndrome.

\begin{tabular}{|c|c|c|}
\hline Moment of the process & Ageist attitudes & Ethic principles \\
\hline Investigation & $\begin{array}{l}\text { The elderly population is underrepresented in clinical trials } \\
\text { Comparing the results of a study between age groups }\end{array}$ & Principle of justice \\
\hline Treatment planning & $\begin{array}{l}\text { Assume survival as the goal of the treatment (some patients } \\
\text { may prefer the quality of life) } \\
\text { Consider the proxies' preferences (instead of patients' pref- } \\
\text { erences) }\end{array}$ & Principle of autonomy \\
\hline Percutaneous revascularization & $\begin{array}{l}\text { Do not do even if indicated } \\
\text { Long and technical informed consent with small letters and } \\
\text { without enough time to consult the family }\end{array}$ & $\begin{array}{l}\text { Principles of beneficence, non- } \\
\text { maleficence, autonomy, and justice }\end{array}$ \\
\hline Medical treatment & Not administering optimal treatment due to high cost & $\begin{array}{l}\text { Principles of beneficence, non- } \\
\text { maleficence, and justice }\end{array}$ \\
\hline Place of admission & Not admitting patients to an acute care unit if needed & $\begin{array}{l}\text { Principles of beneficence, non- } \\
\text { maleficence, and justice }\end{array}$ \\
\hline Discharge & No secondary prevention due to age & Principles of beneficence and justice \\
\hline
\end{tabular}

sidered [22]. The cost and staff required for PCI, and its invasive nature, could be some of the reasons for this discrimination. The elderly have a higher risk of adverse events than middle-aged and younger patients, and they are less likely to receive optimal medical treatment and to undergo coronary angiography and PCI [23].

In the elderly, it is essential to consider the goals of the treatment [24]. ACS at an advanced age is a high-risk condition due to the high risk of adverse events, procedural complications, and mortality [25]. However, comparing the results of a study between age groups solely based on mortality might lead to ageist attitudes. As age is a nonmodifiable risk factor, the question is whether the elderly benefit from a certain treatment, not whether the benefit is higher or lower than in younger patients. Therefore, the correct attitude would be to compare different treatments in similar age groups to avoid ageist attitudes [26]. In addition, we should reflect on all the outcomes of the studies, such as quality of life, since mortality alone might not be the most important objective in this age group.

Some randomized clinical trials compared invasive versus a conservative strategy in elderly patients with nonST-segment-elevation ACS. The After Eighty Study [27], which included 457 patients aged 80 years or older, suggested that an invasive strategy was superior to conservative management, but a large number of patients were excluded due to logistical reasons; so that there may have been an element of selection bias. In addition, the benefit decreased with age, without a clear benefit in nonagenarians. The Italian Elderly ACS trial [28], which included 313 patients aged 75 years or older, failed to show such a benefit. However, NSTEMI patients managed with an invasive strategy had a $57 \%$ reduction in the primary endpoint. The Revascularization or Medical Therapy in Elderly Patients With Acute Anginal Syndromes (RINCAL) trial [29], which included 251 patients $\geq 80$ years, was ter- minated prematurely due to slow recruitment. The early invasive intervention group showed less reinfarction but there was no improvement in survival. In addition, a recent metaanalysis showed that an invasive strategy was associated with a reduction in myocardial infarction [30]. In summary, these studies showed that we should not preclude elderly patients from an invasive strategy based only on chronological age. ACS in the elderly presents with more complex coronary anatomy and a higher risk of associated complications, especially geriatric syndromes (comorbidities, polypharmacy, physical frailty, and cognitive impairment) so that an individual assessment with a patient-centered decision making process is mandatory [31,32]. This should include an invasive approach and revascularization in patients with geriatric syndromes, since a positive influence on outcomes can be achieved [33-39]. The MOSCA trial [40] included 106 patients aged 70 years or older with comorbidities. The results showed that an invasive strategy in older patients with at least two comorbidities did not improve long-term events, although it did decrease mortality at 3 months. The Invasive Versus Conservative Strategy in Frail Patients With NSTEMI (MOSCA-FRAIL) is an ongoing trial involving patients aged 70 years or older with frailty criteria [41]. When it is published, it will help to clarify the appropriate management in frail elderly patients with ACS [41]. However, the previous results from LONGEVO suggested that the benefit in the frail elderly population could be inferior [42].

One reason to avoid an invasive approach or revascularization would be the patient preferences. Although few studies analyzed this issue, most data suggest that the elderly usually accept invasive management when properly explained [26]. In a recent study [43] individual knowledge, preferences, and priorities in invasive cardiac care were noted in 628 patients according to age ( $<75$ years vs. $\geq 75$ years). Older patients had less knowledge of invasive 
care and were less willing to consider cardiac catheterization or PCI. In addition, maintaining cognitive function was a top priority for this population ( $29 \%$ of patients $\geq 85$ years prioritized symptom relief, and losing mental capacity was the top concern). A previous qualitative study including 38 patients [44] showed that elderly patients were likely to follow their cardiologists' recommendations. Although the elderly usually preferred drug treatment to invasive management, they even accepted surgery when needed. Interestingly, this study showed that elderly patients felt that age was a barrier to access a cardiologist consultation, a clear example of ageism. Community-dwelling adults are aware of the potential harms or complications [45]. Stroke is the least acceptable outcome followed by major myocardial infarction, cognitive dysfunction, renal failure, death, prolonged ventilator support, heart failure, angina, sternal wound infection, major bleeding, re-operation, prolonged recovery, cardiac readmission, minor myocardial infarction, and PCI. Of note, clinical decisions were more sensitive to the potential risk of harm than to the potential benefit.

An important issue in older patients undergoing coronary angiography and PCI is informed consent, a materialization of the principle of autonomy. Informed consent is a right of all patients and is regulated by different legislations. It has 7 components: (1) Competence: the ability to understand and decide; (2) Voluntariness: absence of controlling influences among which are coercion, persuasion, and manipulation; (3) Provide and explain the information; (4) Recommend a plan; (5) Understanding the information and the plan; (6) Decision; and (7) Authorization [5]. In some countries, informed consent forms used in cardiology procedures have ethical deficiencies [46]. In older patients, the approach and management may be different resulting in ethical challenges that should be solved using clear communication and eliminating potential obstacles. The elderly should be considered capable of handling their healthcare and making their own decisions, age does not impair the ability to decide. However, information should be individualized, and we should confirm patient comprehension $[47,48]$ since an impaired understanding could be present [49]. Thus, the informed consent should be adapted to patient understanding and linked to the level of education, and personality. Potential communication barriers such as sensorial deficits, cognitive impairment, and other conditions should be considered and an attempt should be made to overcome them by providing aids $[47,48]$. Communication with a family member may reduce anxiety and facilitate the process. More concise forms with fewer technicalities and larger print would be especially helpful for the elderly population. Focusing on the whole decision-making process, effective communication, and a proportionate and individualized approach to consent could improve the experience of many cardiology patients [50]. However, it is important to consider that in life-threatening conditions such as STEMI; time to treatment is critically important, and delaying it due to informed consent may lead to shock and death. In this scenario, clinicians must make a quick and individualized decision and informed consent may be problematic.

Some recommendations on professionalism and ethics have been recently published by the American Heart Association and the American College of Cardiology [51] and should be considered when treating elderly people with ACS and deciding about invasive cardiac care. The concepts of "patient-centered care" and "shared decision process" are of greater interest in this field. Patient-centered care should be "respectful care that responds to the individual preferences of the patient, their needs and values, ensuring that the patient guides all clinical decisions" [52]. The shared decision process is a "structured process that involves the patient and the doctor to generate decisions based on the best evidence and patient preferences" [53]. Signing the informed consent is not enough, we should consider other recommendations to adequately guarantee respect for patients' autonomy: (1) Medical care must be aimed at optimizing results and supporting the values that are most important to the individual. This recommendation is simple when the patient's wishes coincide with the best medical decision. On the other hand, it requires further study, ensuring that the patient understands the situation, in the event of a disagreement. It is also important to explore the cultural values of the patient as imposing patient-centered care in certain cultures may not help and may even be harmful. (2) Clinicians must obtain and document the preferences and values important to the patient, including the goals of treatment. It is important to document the preferences in the medical record so that other team members are aware of them. Also, it is important to develop communication skills to engage in this type of conversation with the patient. (3) The structured shared decision process should be reserved for decisions with significant benefits within reasonable options. (4) The tools to support the formal shared decision process should be designed by a multidisciplinary team, which should include clinicians and patients. (5) Payers and health systems should support policies and infrastructures that facilitate patient-centered care, including the shared decision process when appropriate. The main limitations to implementing this care amongst health care professionals are the lack of time, space, and skills to carry it out, so it must be considered within their work and their remuneration.

Talking to patients about their goals and preferences is essential. In this sense, it may be important to discuss with the patient if he or she wants to live longer or to live better. There is a broad belief that older people prefer the quality of life over the length of life. However, the published results are heterogeneous, and some studies reported the desire of older people to live longer even with poor health [54]. Moreover, families and healthcare providers tend to underestimate these patients' desires for extending 
life [55]. When discussing the quality of life, we should be very cautious and avoid personal preferences or the patient's social worth. It is difficult to state criteria of quality of life with sufficient precision, but some strategies could be considered. For instance, intellectual disability is usually not relevant in determining if the treatment or procedure is in the patient's best interest. Also, and especially for proxies, we should avoid confusing the quality of life for the patients with the value of the patient's life for others [5]. In this sense is important to be cautious to prevent moving to involuntary euthanasia for unconscious or incompetent, non-dying patients, based on the arbitrary and inappropriate quality of life judgments (among them elderly patients) [56]. Quality, results, patient experience, and the reduction of unnecessary tests and procedures are the responsibility of the clinician and should be a high priority [51].

The optimization of medical treatment in ACS could also have ethical implications. In the acute phase of ACS, anti-platelets and anticoagulants are needed [18,19]. However, as previously seen, elderly patients are usually excluded from clinical trials [36]. In this population, clinicians should carefully evaluate bleeding risk [36], comprehensive geriatric assessment, and comorbidities. This assessment should guide the decision regarding the type of $\mathrm{P}_{2} \mathrm{Y}_{12}$ inhibitor, dose, time, and duration (but not the price of the drug). Clopidogrel is the most commonly used antiplatelet agent among the elderly population [57], due to the results of the Study of Platelet Inhibition and Patient Outcomes (PLATO) [58] and in the Trial to Assess Improvement in Therapeutic Outcomes by Optimizing Platelet Inhibition With Prasugrel-Thrombolysis In Myocardial Infarction 38 (TRITON-TIMI 38) [59], due to the increased risk of fatal and intracranial bleeding in this population with prasugrel. In addition, there is a loss of benefit in older patients with prasugrel [60]. However, conflicting results regarding the optimal antithrombotic therapy in the elderly are reported [61-63]. A recently published meta-analysis showed that potent oral $\mathrm{P} 2 \mathrm{Y}_{12}$ inhibitors in elderly patients with ACS reduced the risk of cardiovascular mortality with an increased risk of bleeding events [64]. Secondary prevention should also be considered after discharge.

In the healthcare process, we could also commit ageism when deciding the place of admission (cardiology ward vs. acute care units). Older patients should receive optimal healthcare assistance and should be admitted to an acute care unit if needed. The LONGEVO-SCA registry [65] analyzed 80-year and older patients admitted due to NSTEMI. Almost $30 \%$ of patients were admitted to intensive cardiac care units. Those patients were younger, had acute heart failure or poorer left ventricular ejection fraction, were troponin positive, and had higher punctuation in the ischemic risk scores. Also, they were less frail, had a lower prevalence of other geriatric syndromes, and had more frequently undergone a previous PCI. Those patients with a high risk and higher proportion of invasive treatment had the same clinical outcomes at 6 months as those admitted to the cardiology ward. The authors considered that this might be due to an adequate selection of patients, as those with higher risk had the same prognosis after being admitted to the acute care unit than patients with lower risk admitted to the cardiology ward. A French observational study [66] compared 311 octogenarians and 92 nonagenarians admitted to an intensive care unit for ACS. 5-year mortality was higher for nonagenarians, but no significant difference was found for 5-year cardiovascular mortality. Nonagenarians were less frequently treated with ticagrelor than octogenarians. Older age was related to all-cause mortality (as expected due to the life expectancy at their age) but was not a risk factor for cardiovascular mortality. Although evidence is scarce, chronological age should not be the reason for not admitting patients to acute care units [67-75]. An increasing number of elderly patients are being admitted to intensive care units [76]. The clinical decisions in these units should be based on shared decision-making considering patients' preferences. We should also use a time-limited trial, which means all appropriate intensive care is used and the patient's progress is carefully evaluated to assess if the "maximum" care is continued whether we should consider withdrawing the treatment [76].

However, sometimes there is a need to prioritize patients (as the COVID-19 pandemic has shown) or resources are scarce, and we should decide the treatment for different patients (of different ages) at the same time. In this scenario, we should consider the principle of justice, including social justice, as we will discuss in the next section.

\section{Prioritization, allocation of resources, and the principle of justice}

Prioritization regulates the distribution of limited resources. It does not mean that a person's life is worth more than another, it means allocating the available resources in the most effective way, and to those patients who are most likely to benefit [77]. Resources are limited, so we must prioritize patients respecting the principle of justice.

The principle of justice was initially attributed to Aristotle and states that equals must be treated equally, and unequals must be treated unequally. This is a formal definition that invites some criticism as it does not provide criteria for determining whether two or more individuals are equals or unequals [5]. The term "distributive justice" refers to "fair, equitable, and appropriate distribution of benefits and burdens determined by norms that structure the terms of social cooperation" [5], which is a must clearer concept that addresses the issue of prioritization and considers "social justice" [51]. Social justice is the belief and commitment to guarantee access to quality healthcare for all, which would include the elderly population. The principle of justice requires that physicians and the healthcare systems provide high-quality care to all patients, regardless of their sociodemographic characteristics. 
Table 2. The use of age in prioritization.

\begin{tabular}{|c|c|c|c|}
\hline Strategy & & Definition & Ethics consideration \\
\hline Medical utility & $\begin{array}{l}\text { Probability of success with } \\
\text { the treatment/procedure }\end{array}$ & $\begin{array}{l}\text { Length of time the patient is expected to sur- } \\
\text { vive } \\
\text { Quality-adjusted life-years }\end{array}$ & $\begin{array}{l}\text { Unfair and affects the health of the } \\
\text { elderly }\end{array}$ \\
\hline Health economics & $\begin{array}{l}\text { Cost-effectiveness and } \\
\text { cost-utility analysis }\end{array}$ & $\begin{array}{l}\text { Maximize the action that gets the greatest } \\
\text { health benefit for the money expended }\end{array}$ & Utilitarian goal and discrimination \\
\hline $\begin{array}{l}\text { The "prudent per- } \\
\text { son" theory }\end{array}$ & $\begin{array}{l}\text { Considers the perspective } \\
\text { of an entire life }\end{array}$ & $\begin{array}{l}\text { Resources are allocated throughout all } \\
\text { stages of life }\end{array}$ & $\begin{array}{l}\text { Unfair with the elderly, it would } \\
\text { mean to shift resources to the treat- } \\
\text { ment of younger people }\end{array}$ \\
\hline $\begin{array}{l}\text { The "fair innings" } \\
\text { argument }\end{array}$ & $\begin{array}{l}\text { Considers a person's whole } \\
\text { lifetime experience }\end{array}$ & $\begin{array}{l}\text { Everyone has an equal chance to get fair in- } \\
\text { nings up to a threshold }\end{array}$ & $\begin{array}{l}\text { Even more, discrimination that } \\
\text { health economics system }\end{array}$ \\
\hline
\end{tabular}

Although the concept may be clear, there are some difficulties in prioritizing, some of them according to age. The decisions regarding the allocation of a certain budget can have some effects on other allocations [5]. This may lead to deciding which diseases should receive a priority ranking, and is likely to involve elderly patients. A major problem is allocating scarce resources/treatments for different patients of different ages. Table 2 summarizes the different prioritization strategies according to age. These decisions are even more difficult when an illness is life-threatening and the scarce resource is potentially lifesaving [5], as can happen in a patient suffering from ACS. A hypothetical situation could be deciding which patient (one younger than the other but both with similar medical conditions and functional status) should get a PCI or which of them should be admitted to an acute cardiac care ward. Although this situation is very rare, the COVID-19 pandemic has involved similar situations and priority was given to decisions that maximized survival to discharge and the number of lifeyears saved [78-81].

Various arguments have been proposed to justify the use of age in prioritization. Some of them are based on the probability of success with the treatment or the procedure, which means medical utility. Judgments of the probability of success may include the length of time the patient is expected to survive (shorter for an older patient than for a younger patient) or a strategy of quality-adjusted life-years (younger patients will typically fare better than older patients in the allocation). These forms are unfair and affect the health of the elderly and can result in worsening of their condition. It also results in some uncertainties as to how to judge gains in quality of life. Another strategy is the one that emerged from health economics. This means allocation based on a cost-effectiveness and cost-utility analysis, maximizing that action which results in the greatest health benefit (anticipated health gains) for the money expended. This last strategy also raises objections due to their utilitarian goal and the potential for discrimination [5].

There are different theories to solve this problem: "the prudent person" theory and "the fair-innings" argument
[5,82]. The prudential individual decision [83] considers the perspective of an entire life. Resources should be allocated "prudently" throughout all stages of life within a social system that provides a fair lifetime share of health care for each citizen. This would mean choosing to shift resources that might otherwise be consumed in prolonging the lives of the elderly to the treatment of younger persons. With this theory, the individual chance of living a normal life span (at least) is increased [5]. The "fair-innings" argument considers a person's whole life experience in the context of efforts to achieve equality in the distribution of healthcare. It requires that everyone has an equal chance to get fair innings up to a certain threshold amount; but having reached the threshold, one is no longer entitled to receive socially supported healthcare [5]. This latter theory would mean even more discrimination to the elderly than the ones derived from health economy indicators [84].

On the contrary, other authors are against prioritizing by age $[8,85]$, giving each patient the chance to live to the fullest state, admitting those patients who will benefit the most, independent of age or even the presence of chronic diseases. However, this is not easy to assess, and clinicians may make judgments about the value of each person's life [82]. Considering age to prevent early deaths is supported by a consensus of perspectives (although this does not stop being questionable): prudent individual choice, maximization of societal benefits, and reduction of health disparities [82].

Evidence on prioritization in ACS is scarce. A Swiss study tried to assess which ACS patients' characteristics played a role in prioritizing access to the ICU. They found that prioritization was age-dependent and that the relation between age and probability of admission to the ICU was not linear, with both extremes of age being less likely to be admitted. This age-dependent admission did not change after the implementation of clinical practice guidelines. The authors concluded that rationing is common in clinical practice and that clinical practice guidelines are not completely applied in elderly patients [86]. A previous study had shown similar results in patients with unstable angina [87]. 
In summary, although allocating sources is not easy, a careful evaluation of each patient should be carried out. Conversations with older patients before admission would strengthen beneficence and autonomy [88]. Patients with a minimum expected benefit should not be admitted to intensive care units and even a more careful evaluation is required for those patients with reduced life expectancy [89].

\section{Futility, proportionality, and the principle of non-maleficence}

Medical futility refers to procedures or treatments unlikely to benefit the patient. It is a very frequent problem with ethical implications and concerns about the respect of the principles of non-maleficence, autonomy, and justice [90]. Physicians have no obligation to provide futile treatment. Typically, the term futile refers to a situation in which further treatment provides no medical benefit or is hopeless. It is a term that is related to "proportionality". This refers to that treatment or procedure which is likely to be more burdensome than beneficial, and warrants withdrawing or withholding treatment. This latter involves balancing benefits and risks to the patients. The term "potentially inappropriate" is wider accepted and is used when interventions have at a minimum some chance of success but are not ethically accepted [5].

Concerning futility, we should also consider the "treatment-risk paradox" which means that the higher the patient's risk, the greater the absolute and relative survival advantage from treatment. In patients suffering from ACS, those with higher ischemic risk are those with higher benefits from invasive treatment. However, they are the ones with more conservative management. In the elderly population it could be even more striking as the risk is usually higher. Clinicians are forced to consider the possibility of futility when deciding probably due to healthcare system procurement, infrastructure, and funding. Balancing profit and futility is difficult and decisions should be carried out by multidisciplinary teams $[91,92]$.

In elderly patients with heart disease, futility or nonproportionality of both treatments and procedures must be considered. A comprehensive geriatric assessment [21, 93] and a multidisciplinary team decision are essential to achieve this goal and balance risks and benefits, although this is not always possible in urgent cases. Physicians are not ethically obligated to provide a treatment/procedure that will not benefit their patients [10]. At his point, a conflict between the patient's autonomy and the physician's autonomy may arise. In such a case it would be a conflict between two principles: the principle of non-maleficence and the principle of autonomy. Patients' autonomy is not absolute and the other principles-beneficence, non-maleficence, and justice - should contribute to solving this issue through a shared decision process [94]. However, palliative interventions should be continued in these end-of-life care situations.

\section{Conclusions}

Elderly patients presenting with ACS have some comorbidities that make their treatment a challenge. In this process, different ethical conflicts regarding ageism, prioritization, and futile healthcare may arise. Ageism in the ACS healthcare process could affect the decision of invasive treatment or the admission to the acute care unit. In this regard, the training of physicians in the peculiarities of the elderly patient, comprehensive geriatric assessment, functionality, and frailty are essential for correct decisionmaking. Resource allocation is complicated, but clinicians should consider biological age over chronological age, and age per se should not determine prioritization. Finally, we should avoid futility, but this must be evaluated very carefully since, in many cases, the most seriously ill patients benefit the most from the treatment. Finally, in elderly patients with ACS, it is important to make decisions using a multidisciplinary team, that allows discussion of ethical conflicts to make decisions in the most appropriate way.

\section{Author contributions}

Conceptualization-AA and MMS. Writing, preparing the figures and tables-AA, CB, PDV, SGB, AAS and MMS. Review-AA, CB, PDV, SGB, AAS and MMS.

\section{Ethics approval and consent to participate}

Not applicable.

\section{Acknowledgment}

The authors acknowledge the support of the Section of Geriatric Cardiology of the Spanish Society of Cardiology.

\section{Funding}

This research received no external funding.

\section{Conflict of interest}

The authors declare no conflict of interest. Manuel Martínez-Sellés is serving as one of the Guest editors of this journal. We declare that Manuel Martínez-Sellés had no involvement in the peer review of this article and has no access to information regarding its peer review. Full responsibility for the editorial process for this article was delegated to Peter A. McCullough.

\section{References}

[1] Benjamin EJ, Blaha MJ, Chiuve SE, Cushman M, Das SR, Deo $\mathrm{R}$, et al. Heart Disease and Stroke Statistics-2017 Update: A Report From the American Heart Association. Circulation. 2017; 135: e146-e603.

[2] Townsend N, Nichols M, Scarborough P, Rayner M. Cardiovascular disease in Europe-epidemiological update 2015. European Heart Journal. 2016; 36: 2696-2705.

[3] Ariza Solé A. Síndrome coronario agudo sin elevación del segmento ST. In Díez Villanueva P, (ed.) Manual de cardiopatía 
en el paciente anciano (pp. 81-87). International Marketing \& Communication, S.A: Madrid. 2018.

[4] Bastante Valiente T, Rivero Crespo F, Cuesta Cuesta J, García Guimaraes M, Antuña Álvarez P, Díez Villanueva P, et al. Síndrome coronario agudo con elevación del segmento ST. In Díez Villanueva P, (ed.) Manual de cardiopatía en el paciente anciano (pp. 89-95). International Marketing \& Communication, S.A: Madrid. 2018.

[5] Beauchamp TL, Childress JF, (eds.) Principles of biomedical ethics (pp. 496). 8th edn. Oxford University Press: Nueva York. 2019.

[6] Drane JF. Clinical bioethics: Theory and practice in medical ethical decision making. Sheed \& Ward: Kansas City, MO. 1994.

[7] Domingo Moratalla A. El arte de cuidar. Atender, dialogar y responder (pp. 252). 1st edn. Ediciones Rialp S.A: Madrid. 2013.

[8] Martinez-Sellés D, Martínez- Sellés H, Martínez- Sellés M. Ethical issues in decision-making regarding the elderly affected by coronavirus disease 2019: an expert opinion. European Cardiology. 2020;15: e48.

[9] Chang ES, Kannoth S, Levy S, Wang S, Lee JE, Levy BR. Global reach of ageism on older persons' health: a systematic review. PLoS ONE. 2020;15: e0220857.

[10] Tadd W, Bayer A. Commentary: medical decision making based on chronological age-cause for concern. The Journal of Clinical Ethics. 2000; 11: 328-333.

[11] Lipman HI. Ethical issues in the managements of geriatric cardiac patients. The American Journal of Geriatric Cardiology. 2006;15: 379-381.

[12] Ebrahim S. Do not resuscitate decisions: flogging dead horses or a dignified death? British Medical Journal. 2000; 320: 11551156.

[13] Brockmann H. Why is less money spent on health care for the elderly than for the rest of the population? Health care rationing in German hospitals. Social Science \& Medicine. 2002; 55: $593-$ 608.

[14] Asch SM, Kerr EA, Keesey J, Adams JL, Setodji CM, Malik S, et al. Who is at greatest risk for receiving poor-quality health care? The New England Journal of Medicine. 2006; 354: 11471156.

[15] Paradies Y. A systematic review of empirical research on selfreported racism and health. International Journal of Epidemiology. 2006; 35: 888-901.

[16] Bozzaro C, Boldt J, Schweda M. Are older people a vulnerable group? Philosophical and bioethical perspectives on aging and vulnerability. Bioethics. 2018; 32: 233-239.

[17] Dégano IR, Elosua R, Marrugat J. Epidemiology of acute coronary syndromes in Spain: estimation of the number of cases and trends from 2005 to 2049. Revista Espanola De Cardiologia. 2013; 66: 472-481.

[18] Collet JP, Thiele H, Barbato E, Barthélémy O, Bauersachs J, Bhatt DL, et al. ESC Scientific Document Group. 2020 ESC guidelines for the management of acute coronary syndromes in patients presenting without persistent ST-segment elevation. European Heart Journal. 2021; 42: 1289-1367.

[19] Ibanez B, James S, Agewall S, Antunes MJ, Bucciarelli-Ducci C, Bueno H, et al. ESC Scientific Document Group. 2017 ESC guidelines for the management of acute myocardial infarction in patients presenting with ST-elevation: the task force for the management of acute myocardial infarction in patients presenting with ST-segment elevation of the European Society of Cardiology (ESC). European Heart Journal. 2018; 39: 119-177

[20] Kragholm K, Goldstein SA, Yang Q, Lopes RD, Schulte PJ, Bernacki GM, et al. Trends in Enrollment, Clinical Characteristics, Treatment, and Outcomes According to Age in Non-STSegment-Elevation Acute Coronary Syndromes Clinical Trials. Circulation. 2016; 133: 1560-1573.
[21] Díez-Villanueva P, Arizá-Solé A, Vidán MT, Bonanad C, Formiga F, Sanchis J, et al. Recommendations of the Geriatric Cardiology Section of the Spanish Society of Cardiology for the Assessment of Frailty in Elderly Patients with Heart Disease. Revista Espanola De Cardiologia. 2019; 72: 63-71.

[22] Alexander KP, Newby LK, Bhapkar MV, White HD, Hochman JS, Pfisterer ME, et al. International variation in invasive care of the elderly with acute coronary syndromes. European Heart Journal. 2006; 27: 1558-1564.

[23] Collinson J, Bakhai A, Flather MD, Fox KA. The management and investigation of elderly patients with acute coronary síndromes without ST elevation: an evidence-based approach? Results of the Prospective Registry of Acute Ischaemic Syndromes in the United Kingdom (PRAIS-UK). Age Ageing. 2005; 34: 61-66.

[24] Jiménez-Méndez C, Díez-Villanueva P, Alfonso F. Non-ST segment elevation myocardial infarction in the elderly. Reviews in Cardiovascular Medicine. 2021; 22: 779.

[25] Kumar S, McDaniel M, Samady H, Forouzandeh F. Contemporary Revascularization Dilemmas in Older Adults. Journal of the American Heart Association. 2020; 9: e014477.

[26] Elder AT. Which benchmarks for age discrimination in acute coronary syndromes? Age and Ageing. 2005; 34: 4-5.

[27] Tegn N, Abdelnoor M, Aaberge L, Endresen K, Smith P, Aakhus $\mathrm{S}$, et al. Invasive versus conservative strategy in patients aged 80 years or older with non-ST elevation myocardial infarction or unstable angina pectoris (After Eighty study): an open-label randomized controlled trial. Lancet. 2016; 387: 1057-1065.

[28] Savonitto S, Cavallini C, Petronio AS, Murena E, Antonicelli $\mathrm{R}$, Sacco A, et al. Early aggressive versus initially conservative treatment in elderly patients with non-ST-segment elevation acute coronary syndrome: a randomized controlled trial. JACC: Cardiovascular Interventions. 2012; 5: 906-916.

[29] de Belder A, Myat A, Blaxill J, Haworth P, O'Kane PD, Hatrick $\mathrm{R}$, et al. Revascularisation or medical therapy in elderly patients with acute anginal syndromes: the RINCAL randomised trial. EuroIntervention. 2021; 17: 67-74.

[30] Garg A, Garg L, Agarwal M, Rout A, Raheja H, Agrawal S, et al. Routine Invasive Versus Selective Invasive Strategy in Elderly Patients Older than 75 Years with Non-ST-Segment Elevation Acute Coronary Syndrome: a Systematic Review and Meta-Analysis. Mayo Clinic Proceedings. 2018; 93: 436-444.

[31] Bendz B, Aaberge L. Acute coronary syndromes in older patients: does older age matter? The Lancet. 2020; 396: 585-587.

[32] Kayani WT, Khan MR, Deshotels MR, Jneid H. Challenges and Controversies in the Management of ACS in Elderly Patients. Current Cardiology Reports. 2020; 22: 51.

[33] Blanco S, Ferrières J, Bongard V, Toulza O, Sebai F, Billet S, et al. Prognosis Impact of Frailty Assessed by the Edmonton Frail Scale in the Setting of Acute Coronary Syndrome in the Elderly. The Canadian Journal of Cardiology. 2017; 33: 933-939.

[34] Alonso Salinas GL, Sanmartín Fernández M, Pascual Izco M, Marco del Castillo Á, Rincón Díaz LM, Lozano Granero C, et $a l$. Frailty predicts major bleeding within 30 days in elderly patients with Acute Coronary Syndrome. International Journal of Cardiology. 2016; 222: 590-593.

[35] White HD, Westerhout CM, Alexander KP, Roe MT, Winters KJ, Cyr DD, et al. Frailty is associated with worse outcomes in nonST-segment elevation acute coronary syndromes: Insights from the TaRgeted platelet Inhibition to cLarify the Optimal strateGy to medicallY manage Acute Coronary Syndromes (TRILOGY ACS) trial. European Heart Journal. Acute Cardiovascular Care. 2016; 5: 231-242.

[36] Ariza-Solé A, Guerrero C, Formiga F, Aboal J, Abu-Assi E, Marín F, et al. Global Geriatric Assessment and in-Hospital Bleeding Risk in Elderly Patients with Acute Coronary Syn- 
dromes: Insights from the LONGEVO-SCA Registry. Thrombosis and Haemostasis. 2018; 118: 581-590.

[37] Núñez JE, Núñez E, Fácila L, Bertomeu V, Llàcer A, Bodí V, et al. Prognostic value of Charlson comorbidity index at 30 days and 1 year after acute myocardial infarction. Revista Espanola De Cardiologia. 2004; 57: 842-849. (In Spanish)

[38] Kwok CS, Martinez SC, Pancholy S, Ahmed W, Al-Shaibi K, Potts J, et al. Effect of Comorbidity on Unplanned Readmissions after Percutaneous Coronary Intervention (from the Nationwide Readmission Database). Scientific Reports. 2018; 8: 11156.

[39] Sanchis J, García Acuña JM, Raposeiras S, Barrabés JA, Cordero A, Martínez-Sellés M, et al. Comorbidity burden and revascularization benefit in elderly patients with acute coronary syndrome. Revista Española De Cardiología. 2020; 74: 765772.

[40] Sanchis J, Núñez E, Barrabés JA, Marín F, Consuegra-Sánchez $\mathrm{L}$, Ventura $\mathrm{S}$, et al. Randomized comparison between the invasive and conservative strategies in comorbid elderly patients with non-ST elevation myocardial infarction. European Journal of Internal Medicine. 2016; 35: 89-94.

[41] Sanchis J, Ariza-Solé A, Abu-Assi E, Alegre O, Alfonso F, Barrabés JA, et al. Invasive Versus Conservative Strategy in Frail Patients with NSTEMI: the MOSCA-FRAIL Clinical Trial Study Design. Revista Espanola De Cardiologia. 2019; 72: 154159.

[42] Llaó I, Ariza-Solé A, Sanchis J, Alegre O, López-Palop R, Formiga $\mathrm{F}$, et al. Invasive strategy and frailty in very elderly patients with acute coronary syndromes. EuroIntervention. 2018; 14: e336-e342.

[43] Nanna MG, Peterson ED, Wu A, Harding T, Galanos AN, Wruck $\mathrm{L}$, et al. Age, knowledge, preferences, and risk tolerance for invasive cardiac care. American Heart Journal. 2020; 219: 99108.

[44] Kennelly C, Bowling A. Suffering in deference: a focus group study of older cardiac patients' preferences for treatment and perceptions of risk. Quality in Health Care. 2001; 10: i23-i28.

[45] Zhang G, Parikh PB, Zabihi S, Brown DL. Rating the preferences for potential harms of treatments for cardiovascular disease: a survey of community-dwelling adults. Medical Decision Making. 2013; 33: 502-509.

[46] Çelebi AS, Ekmekçi PE, Güner MD. Ethical evaluation of informed consent forms used in cardiology clinics and the importance of institutional standardized approach. Turk Kardiyoloji Dernegi Arsivi. 2021; 49: 477-487.

[47] Giampieri M. Communication and informed consent in elderly people. Minerva Anestesiologica. 2012; 78: 236-242.

[48] Sullivan EE. Issues of informed consent in the geriatric population. Journal of Perianesthesia Nursing. 2004; 19: 430-432.

[49] Sugarman J, McCrory DC, Hubal RC. Getting meaningful informed consent from older adults: a structured literature review of empirical research. Journal of the American Geriatrics Society. 1998 ; 46: 517-524.

[50] Bromage DI, Lim J, ter Meulen R, Ramcharitar S. Improving informed consent in percutaneous coronary revascularisation. EuroIntervention. 2012; 8: 146-154.

[51] Benjamin IJ, Valentine CM, Oetgen WJ, Sheehan KA, Brindis RG, Roach WH Jr, et al. 2020 American Heart Association and American College of Cardiology consensus conference on professionalism and ethics: a consensus conference report. Journal of the American College of Cardiology. 2021; ;77: 3079-3133.

[52] Institute of Medicine Committee on Quality of Health Care in America. Crossing the Quality Chasm: A New Health System for the 21st Century. National Academies Press: Washington (DC). 2001

[53] National Quality Forum. National Standards for the Certification of Patient Decision Aids. 2016. Available at: https:
//www.qualityforum.org/Publications/2016/12/National_Sta ndards_for_the_Certification_of_Patient_Decision_Aids.aspx (Accessed: 28 August 2021).

[54] Tsevat J, Dawson NV, Wu AW, Lynn J, Soukup JR, Cook EF, et al. Health values of hospitalized patients 80 years or more. HELP Investigators. Hospitalized elderly longitudinal project. Journal of the American Medical Association. 1998; 279: 371375.

[55] Hamel MB, Lynn J, Teno JM, Covinsky KE, Wu AW, Galanos $\mathrm{A}$, et al. Age-related differences in care preferences, treatment decisions, and clinical outcomes of seriously ill hospitalized adults: lessons from SUPPORT. Journal of the American Geriatrics Society. 2000; 48: S176-S182.

[56] Ramsey P. Ethics at the edges of life: medical and legal intersections. Yale University Press: New Haven, CT. 1978.

[57] Danchin N, Lettino M, Zeymer U, Widimsky P, Bardaji A, Barrabes JA, et al. Use, patient selection and outcomes of P2Y12 receptor inhibitor treatment in patients with STEMI based on contemporary European registries. European Heart Journal: Cardiovascular Pharmacotherapy. 2016; 2: 152-167.

[58] Wallentin L, Becker RC, Budaj A, Cannon CP, Emanuelsson $\mathrm{H}$, Held C, et al. Ticagrelor versus Clopidogrel in Patients with Acute Coronary Syndromes. New England Journal of Medicine. 2009; 361: 1045-1057.

[59] Wiviott SD, Braunwald E, McCabe CH, Montalescot G, Ruzyllo W, Gottlieb S, et al. Prasugrel versus Clopidogrel in Patients with Acute Coronary Syndromes. New England Journal of Medicine. 2007; 357: 2001-2015.

[60] Husted S, James S, Becker RC, Horrow J, Katus H, Storey RF, et al. Ticagrelor versus clopidogrel in elderly patients with acute coronary syndromes: a substudy from the prospective randomized PLATelet inhibition and patient Outcomes (PLATO) trial. Circulation: Cardiovascular Quality and Outcomes. 2012; 5: 680-688.

[61] Szummer K, Montez-Rath ME, Alfredsson J, Erlinge D, Lindahl $\mathrm{B}$, Hofmann R, et al. Comparison between Ticagrelor and Clopidogrel in Elderly Patients with an Acute Coronary Syndrome: Insights from the SWEDEHEART registry. Circulation. 2020; 142: $1700-1708$.

[62] Gimbel M, Qaderdan K, Willemsen L, Hermanides R, Bergmeijer T, de Vrey E, et al. Clopidogrel versus ticagrelor or prasugrel in patients aged 70 years or older with non-ST-elevation acute coronary syndrome (POPular AGE): the randomised, openlabel, non-inferiority trial. The Lancet. 2020; 395: 1374-1381.

[63] Gragnano F, Moscarella E, Calabrò P, Cesaro A, Pafundi PC, Ielasi $\mathrm{A}$, et al. Clopidogrel versus ticagrelor in high-bleeding risk patients presenting with acute coronary syndromes: insights from the multicenter START-ANTIPLATELET registry. Internal and Emergency Medicine. 2021; 16: 379-387.

[64] Abusnina W, Al-Abdouh A, Bizanti A, Gauravpal G, Houssien A, Alshebani Y, et al. Ischemic and bleeding outcomes of potent P2Y12 inhibitor platelet agents versus clopidogrel in elderly patients with acute coronary syndrome: a meta-analysis of randomized trials. American Heart Journal. 2018; 195: 78-85.

[65] Lorente V, Ariza-Solé A, Jacob J, Formiga F, Marín F, MartínezSellés M, et al. Criterios de ingreso en unidades de críticos del paciente anciano con síndrome coronario agudo desde los servicios de urgencias hospitalarios de España. Estudio de cohorte LONGEVO-SCA. Emergencias. 2019; 31: 154-160.

[66] Kochly F, Haddad C, Harbaoui B, Falandry C, Lantelme P, Courand P. Therapeutic management and outcome of nonagenarians versus octogenarians admitted to an intensive care unit for acute coronary syndromes. Archives of Cardiovascular Diseases. 2020; 113: 780-790.

[67] Andersen FH, Flaatten H, Klepstad P, Follestad T, Strand K, Krüger AJ, et al. Long-Term Outcomes after ICU Admission 
Triage in Octogenarians. Critical Care Medicine. 2017; 45: e363-e371.

[68] de Lange DW, Brinkman S, Flaatten H, Boumendil A, Morandi $\mathrm{A}$, Andersen $\mathrm{FH}$, et al. Cumulative prognostic score predicting mortality in patients older than 80 years admitted to the ICU. Journal of the American Geriatrics Society. 2019; 67: $1263-$ 1267.

[69] Flaatten H, De Lange DW, Morandi A, Andersen FH, Artigas A, Bertolini G, et al. The impact of frailty on ICU and 30-day mortality and the level of care in very elderly patients $(\geq 80$ years). Intensive Care Medicine. 2017; 43: 1820-1828.

[70] Guidet B, Vallet H, Boddaert J, de Lange DW, Morandi A, Leblanc G, et al. Caring for the critically ill patients over 80 : a narrative review. Annals of Intensive Care. 2018; 8: 114

[71] Fronczek J, Polok KJ, Nowak-Kózka I, Włudarczyk A, Górka $\mathrm{J}$, Czuczwar M, et al. Frailty is associated with an increased mortality among patients $\geq 80$ years old treated in Polish ICUs. Anaesthesiology Intensive Therapy. 2018; 50: 245-251.

[72] Ferrante LE, Pisani MA, Murphy TE, Gahbauer EA, LeoSummers LS, Gill TM. Functional trajectories among older persons before and after critical illness. JAMA Internal Medicine. 2015; 175: 523-529.

[73] Angus DC. Admitting Elderly Patients to the Intensive Care Unit-is it the Right Decision? JAMA. 2017; 318: 1443-1444.

[74] Martínez-Sellés M, Datino T, Bueno H. Coronary care unit admission of very old patients with acute myocardial infarction. Heart Journal of the American Medical Association. 2006; 92: 549-550.

[75] Martínez-Sellés M, Datino T, Bueno H. Influence of reperfusion therapy on prognosis in patients aged $>$ or $=89$ years with acute myocardial infarction. American Journal of Cardiology. 2005; 95: 1232-1234.

[76] van Heerden PV, Sviri S, Beil M, Szczeklik W, de Lange D, Jung $\mathrm{C}$, et al. The wave of very old people in the intensive care unita challenge in decision-making. Journal of Critical Care. 2020; 60: 290-293.

[77] Mannelli C. Whose life to save? Scarce resources allocation in the COVID-19 outbreak. Journal of Medical Ethics. 2020; 46: 364-366.

[78] Emanuel EJ, Persad G, Upshur R, Thome B, Parker M, Glickman A, et al. Fair Allocation of Scarce Medical Resources in the Time of Covid-19. New England Journal of Medicine. 2020; 382: 2049-2055.

[79] White DB, Lo B. A Framework for Rationing Ventilators and Critical Care Beds during the COVID-19 Pandemic. Journal of the American Medical Association. 2020; 323: 1773.

[80] Farrell TW, Ferrante LE, Brown T, Francis L, Widera E, Rhodes
$\mathrm{R}$, et al. AGS position statement: resource allocation strategies and age-related considerations in the COVID-19 era and beyond. Journal of American Geriatrics Society. 2020; 68: 1136-1142.

[81] Vinay R, Baumann H, Biller-Andorno N. Ethics of ICU triage during COVID-19. British Medical Bulletin. 2021; 138: 5-15.

[82] Persad G, Joffe S. Allocating scarce life-saving resources: the proper role of age. Journal of Medical Ethics. 2021; 47: 836838.

[83] Daniels N. Just health: meeting health needs fairly. Cambridge University Press: New York. 2008.

[84] Williams A. Intergenrational Equity: An Exploration of the "Fair Innings" argument. Health Economics. 1997; 6: 117-132.

[85] Archard D, Caplan A. Is it wrong to prioritise younger patients with covid-19? British Medical Journal. 2020; 369: m1509.

[86] Wasserfallen JB, Pinget C, Berger A, Eckert P, Stauffer JC, Gillis $\mathrm{D}$, et al. Impact of clinical practice guidelines on prioritisation for allocation of intensive care beds in high-risk acute coronary syndrome patients: does age play a role? Swiss Medical Weekly. 2006; 136: 655-658.

[87] Shahi CN, Rathore SS, Wang Y, Thakur R, Wu WC, Lewis JM, et al. Quality of care among elderly patients hospitalised with unstable angina. American Heart Journal. 2001; 142: 263-270.

[88] Ho EP, Neo H. COVID 19: prioritise autonomy, beneficence and conversations before score-based triage. Age and Ageing. 2021; 50: $11-15$.

[89] Bonanad C, García-Blas S, Tarazona-Santabalbina FJ, DíezVillanueva P, Ayesta A, Sanchís Forés J, et al. Coronavirus: the geriatric emergency of 2020. Joint document of the Geriatric Cardiology Section of the Spanish Society of Cardiology and the Spanish Society of Geriatrics and Gerontology. Revista Española de Cardiología. 2020; 73: 569-576.

[90] Romanò M. Futility in Cardiology. Giornale Italiano Di Cardiologia. 2016; 17: 6-10. (In Italian)

[91] Roffi M, Mukherjee D. Treatment-risk paradox in acute coronary syndromes. European Heart Journal. 2018; 39: 3807-3809.

[92] Ahrens I, Averkov O, Zúñiga EC, Fong AYY, Alhabib KF, Halvorsen $\mathrm{S}$, et al. Invasive and antiplatelet treatment of patients with non-ST-segment elevation myocardial infarction: Understanding and addressing the global risk-treatment paradox. Clinical Cardiology. 2019; 42: 1028-1040.

[93] Demurtas J, Ecarnot F, Cernesi S, Solari M, Munoz MA, Cella A. Comprehensive Geriatric Assessment in Cardiovascular Disease. Advances in Experimental Medicine and Biology. 2020; 56: 87-97.

[94] Olmstead JA, Dahnke MD. The need for an effective process to resolve conflicts over medical futility: a case study and analysis. Critical Care Nurse. 2016; 36: 13-23. 